\title{
El fallo en el sostén y la pérdida de subjetividad en Alejandra Pizarnik. Un análisis desde la teoría psicoanalítica winnicottiana ${ }^{1}$
}

\author{
Marina Espada Vadillo \\ Psicóloga, Madrid.
}

En este trabajo analizamos las narrativas que surgen de la poética pizarnikiana a través de la teoría psicoanalítica de Winnicott, cuya problemática central es el vínculo como constructor de la subjetividad. Nuestra hipótesis es que en la poética de Pizarnik se observan las consecuencias de un yo escindido debido a un fallo en el sostén tal y como apunta Winnicott en su obra. A partir de este problema principal del fallo en el sostén, y su esclarecimiento en la obra de Pizarnik, desarrollaremos cuatro puntos en que se articularán las consecuencias de este fallo en el sostén que se da en el vínculo primario. Estos cuatro puntos, que se derivan de las líneas principales del trabajo de Winnicott, y que son esenciales para la tarea de análisis de las narrativas de Pizarnik, son los siguientes: disociación, imposibilidad de una relación con el mundo, futilidad de la existencia del falso Self y miedo al derrumbe.

Palabras clave: vínculo, sostén, disociación, miedo al derrumbe, Falso Self, subjetividad, espacio transicional

In this paper we analyze the narratives that emerge from the Pizarnikian poetics through Winnicott's psychoanalytic theory, whose central problematic is the link as the constructor of subjectivity. Our hypothesis is that in the poetics of Pizarnik the consequences of a split ego are observed due to a failure in the support, as Winnicott points out in his work. From this main problem of failure in the support, and its clarification in the work of Pizarnik, we will develop four points that will articulate the consequences of this failure in the support that occurs in the primary link. These four points, which are derived from the main lines of Winnicott's work, and which are essential for the labour of analyzing Pizarnik's narratives, are the following: dissociation, impossibility of a relationship with the world, futility of the existence of the false self and fear of collapse.

Key Words: link, support, dissociation, fear of breakdown, false self, subjectivity, transitional space

English Title: The failure in the support and the loss of subjectivity in Alejandra Pizarnik. An analysis from the Winnicottian psychoanalytic theory.

\section{Cita bibliográfica / Reference citation:}

Espada Vadillo, M. (2018). El fallo en el sostén y la pérdida de subjetividad en Alejandra Pizarnik. Un análisis desde la teoría psicoanalítica winnicottiana. Clínica e Investigación Relacional, 12 (3): 513529. [ISSN 1988-2939] [Recuperado de www.ceir.info ] DOI: 10.21110/19882939.2018.120306

\footnotetext{
${ }^{1}$ Este artículo se basa en el Trabajo Fin de Grado en Psicología realizado por la autora en la Facultad de Psicología de la Universidad Complutense, bajo la tutoría del Prof. Alejandro Ávila.

${ }^{2}$ Graduada en Psicología, UCM. Dirección de contacto: marespoz@ucm.es
} 


\section{Introducción.}

El presente trabajo surge de la intención de reflexionar el problema de la importancia del vínculo y de la relación dialéctica en la construcción de la realidad y del sí-mismo, así como remarcar la importancia de estos en la génesis del sufrimiento adulto. Lo hacemos en el sentido en que lo hace el psicoanálisis relacional: el vínculo como hilo conductor de la subjetividad. Nos ubicamos por tanto en la reformulación que el psicoanálisis relacional hace de la teoría clásica freudiana, en concreto, el principio de esta corriente de centrar la atención ya no tanto en el mundo intrapsíquico, como en la relación, en el vínculo, que se entiende como el origen de la psique. Hemos querido tratar este problema a través de la lectura de la obra de uno de los fundadores de este pensamiento relacional: D.W. Winnicott, quien pone en el centro de su obra el problema del vínculo a través del concepto fundamental de sostén. Recogemos la hipótesis de Winnicott: un fallo recurrente en el sostén, ese vínculo primario, tiene como consecuencia una desorganización del psiquismo en el adulto, una desarticulación de su subjetividad.

Hemos querido investigar este problema y así reflexionar sobre él, en la figura de la poeta Alejandra Pizarnik por dos motivos. El primero de ellos es que el psicoanálisis nos brinda una buena herramienta para el análisis de narrativas, en especial las poéticas, ya que bajo su mirada supone en ellas la expresión del inconsciente. La poética de Pizarnik nos parece en este sentido el lugar idóneo en el que constatar la productividad del psicoanálisis como herramienta de estudio de las narrativas poéticas. Esta poética de Pizarnik además se nos muestra reveladora en su doble aspecto: en las Poesías tenemos una viva expresión inconsciente de la subjetividad perdida de la poeta, difícilmente comunicable por otro medio, y en los Diarios tenemos una narración autobiográfica que ahonda en los problemas relacionales que van tejiendo su identidad. Por consiguiente, el segundo de los motivos para investigar la obra pizarnikiana es que, como trataremos de demostrar, es un buen correlato poético de algunos de los ejes más sustanciales de la obra de Winnicott; la obra de Pizarnik es una expresión, a veces autoreflexiva, de ruptura del ser (discontinuidad existencial) y un intento de reconstrucción de ese ser, así como una constatación de pérdida de subjetividad y un reflejo de constantes desencuentros originados en problemas relacionados con el vínculo.

La relación entre psicoanálisis y literatura es amplia y compleja, por conveniencia mencionaremos simplemente el hecho de que la corriente surrealista bebe del emergente psicoanálisis, corriente (el surrealismo) de la que Alejandra Pizarnik obtiene gran influencia. Ésta se puede observar en la brevedad de sus poemas, caracterizados por la concisión y por la expresión de conjuntos de imágenes que son experimentadas como impactos 
emocionales y visuales (Vindel Saez, 2016). Se dice que esta corriente adquiere en la obra de Pizarnik más importancia en el final de su vida, por su gran afán de conquista de lo real, lo cual es un factor clave del movimiento surrealista, pero que en Pizarnik, además, llega a ser una auténtica forma de ser (ibíd.). Este afán de conquista de lo real define lo que venimos defendiendo sobre la intención de Pizarnik con la palabra: esa incesante búsqueda de identidad y esa voluntad de vuelta a la realidad del cuerpo, que no es sino un intento de reconstrucción de esa subjetividad perdida. Alejandra refleja de sí misma haber sido una niña triste y solitaria, y en sus Diarios se puede ver reflejada esa infancia perdida: "Fantasías de una infancia que no tuve, sobre la madre que no tuve" (Pizarnik, 2013). Era una chica introvertida, tartamudeaba, tenía problemas de acné y tendencia a engordar (esto último le llevó a una adicción a las anfetaminas), todo ello fue quebrando su autoestima y pronunciando esa introversión. Su poesía es una clara expresión de su vida interior, de su gran obsesión por llegar al fondo de sí misma (a una reconstrucción de su ser) y por encontrar la causa de su sufrimiento, ésta última en forma de una constante pregunta: "¿Por qué este eterno sufrir?" (Pizarnik, 2013). El yo busca explicarse en Pizarnik, y es tal su obsesión, que puede verse en sus escritos cómo llega a un profundo ensimismamiento. Pero las palabras no sirven, dice Pizarnik: El lenguaje no sirve, "las "palabras de este mundo" no alcanzan a nombrar la experiencia del yo dentro del yo" (Magliano, 2005).

Como hemos apuntado, Winnicott y Pizarnik tratan una problemática parecida y sus obras parecen tener algunos puntos de encuentro; ambos tratan temas de la existencia muy afines y procesos internos semejantes como la caída, la fragmentación, el vacío, la angustia existencial, la infancia o la orfandad. Pizarnik anota en sus Diarios: "El sentimiento de la soledad y del abandono es una enfermedad ¿Cuándo comienza? ¿Por qué no hubo una madre para impedirla? Pero tal vez esta enfermedad es justamente que no hubo una madre para impedirla" (Pizarnik, 2013). Estas líneas serían suscritas perfectamente por Winnicott, para quien todo un conjunto de estados desde la patología psicótica hasta estados normales de salud, dependen de la función fundamental del sostén que ejerce la madre como papel crucial en la construcción de la intersubjetividad. Winnicott es denominado por André Green, el psicoanalista de lo fronterizo; los pacientes esquizoides y fronterizos, "se gestan en los desencuentros y en las separaciones, se nutren de ausencias" (Nemirovsky, 2007). Pizarnik parece ser un buen ejemplo de caracterización de esos desencuentros y ausencias, y queremos apuntar además la genial intuición que ella misma tuvo acerca de la causa de su sufrimiento, su sensación de vacío, de inexistencia y abandono.

Como decimos, la función del sostén fallida (ausencia de un yo auxiliar que satisfaga las necesidades del yo), parece estar descrita con precisión en algunas narrativas de Pizarnik, en sus Diarios y en sus creaciones poéticas, y así lo vamos a tratar de exponer. Así pues, 
queremos remarcar que el concepto de sostén será el hilo conductor de este trabajo. En primer lugar definiremos brevemente la función del sostén, en cuyas consecuencias profundizaremos seguidamente en la segunda parte del trabajo, de la mano de los escritos pizarnikianos. Vamos a tratar de desplegar, en esta segunda parte, a lo largo de cuatro puntos, el desarrollo de un proceso que desemboca en una pérdida de subjetividad, proceso que muestra la importancia del vínculo en la construcción del psiquismo, y vamos a tratar de alumbrar este proceso en las narrativas de Pizarnik. Nos vamos a encontrar, tanto en sus Diarios como en su poética, con una escritura autobiográfica, a través de la cual Pizarnik va a intentar construir una identidad; citando a Calafell se trata de "la puesta en escena de una identidad que se dibuja en el verso y el reverso de su propia estructura, revelando las fisuras de una escritura que si bien se concibe como el lugar de enajenación y de muerte, se descubre también como espacio de reencuentro y de reconocimiento: de una subjetividad en contacto constante consigo misma y con su otredad" (Calafell, 2007).

\section{El concepto de sostén.}

Sostén es el conjunto de cuidados y apoyos que se dan en el vínculo madre-bebé, conjunto de cuidados necesarios en las etapas tempranas para un desarrollo adecuado del psiquismo. La función del sostén tiene que ver, en parte importante, con la protección de las agresiones fisiológicas y psicológicas que se irán complejizando con el tiempo, en definitiva tiene que ver con la buena satisfacción de las necesidades del yo. Un fallo en el sostén implica que esos cuidados no se satisfacen adecuadamente, acontecimiento que tiene devastadoras consecuencias para el psiquismo del bebé. Es importante señalar que cuando se habla de fallo no nos referimos a un acontecimiento preciso y concreto sino a "una reiteración de desencuentros que cobrarán carácter traumático como constantes del vínculo" (Abello Blanco y Liberman, 2011). Una de las características de este tipo de trauma es "que cursa silenciosamente al no poseer el carácter puntual y dramático de lo que se ha denominado trauma shock" (ibíd.).

Un buen sostén posibilita en el bebé la ilusión de omnipotencia. Esta ilusión de omnipotencia es una visión mágica del niño acerca del mundo. Éste siente que crea el ambiente de objetos de su entorno; esta ilusión se hace posible gracias a una lectura correcta de sus necesidades por parte de la madre, la cual le presenta aquello que necesita cuando lo necesita y cuando no, se lo retira. La ilusión es necesaria pues permitirá crear un ámbito de experiencia donde se estará en contacto con el mundo exterior, por lo tanto, permitirá un vínculo con el mundo externo y una sana diferenciación con él. La situación contraria, es decir, un fallo en el sostén, una mala lectura de sus necesidades, supone para 
el bebé una intrusión o amenaza por parte del entorno (aquello que necesita el niño, cuando lo quiere no le es presentado, y cuando no lo quiere le es presentado). Si la madre falla y esta intrusión supera la capacidad del bebé para afrontarla, la psique no se desarrollará adecuadamente, y habrá una interrupción de la continuidad existencial en el bebé. Así pues queremos remarcar que al fallar el sostén se interrumpe la continuidad existencial y el yo organiza defensas contra la intrusión ambiental; una de esas defensas es la escisión del yo. Estas defensas a su vez, generarán una nueva amenaza al núcleo del self, aunque estén destinadas a protegerlo (Winnicott, 2006a). Encontraremos en Pizarnik esa escisión o ruptura del yo que trata de lidiar con el vacío. ¿Cómo?, según Nuria Calafell (2007), citando a Barthes, "a través de los fragmentos: «Escribir por fragmentos: los fragmentos son entonces las piedras sobre el borde del círculo: me explayo en redondo: todo mi pequeño universo está hecho migajas: en el centro, ¿qué?»" (Barthes, 2004). En el centro nada, diría Winnicott, pues este centro es el núcleo donde se encuentra el self verdadero que quedó vacío y enterrado tras la escisión, protegido por el falso self que se desarrolla en su lugar, concepto este también que explicaremos más adelante en relación a Pizarnik.

Lo que brindará la ilusión de omnipotencia, y por tanto lo que brindará el sostén al niño, es la esperanza de que existe una realidad exterior que corresponde a su necesidad. Una vez se hayan dado suficientes encuentros para que el niño adquiera la capacidad de ilusión, es papel de la madre ir desilusionándole. Esto significa ir introduciendo la realidad (no-yo) de forma que progresivamente se introduzca la diferenciación yo-no yo. La presentación de la realidad al niño se introduce gradualmente a través de fallos en el sostén tolerables que permiten enfrentarse al inmenso shock de la pérdida de omnipotencia; y aunque "la tarea de aceptación de la realidad nunca es completada" (Winnicott, 1999a), si todo va bien (buen sostén), se genera el espacio transicional. La función del espacio transicional es aliviar la tensión interior-exterior, es decir, permite soportar la realidad, y no sólo actúa como regulador del complicado proceso de separarse, sino que además, permite seguir sintiendo ese vínculo con la madre/ambiente del que el bebé se ha separado y diferenciado como algo significativo. El espacio transicional permite, por lo tanto, ilusionarse con el exterior tras la desilusión de omnipotencia.

Habiendo comprendido este proceso de sostén, comprenderemos mejor qué ocurre cuando hay un fallo en éste. En este artículo mencionaremos en cuatro puntos las consecuencias que se derivan de este proceso y que leemos en la poesía de Pizarnik, cuatro puntos de unión entre el marco teórico winnicottiano y las problemáticas que se dan en Pizarnik. 


\section{Consecuencias derivadas de un fallo en el sostén y su esclarecimiento en la obra de Pizarnik.}

II. 1. Disociación y búsqueda de la identidad a través del cuerpo en Winnicott y su reflejo en Pizarnik.

La primera de las consecuencias del fallo en el sostén que vamos a tratar es la disociación. ¿En qué consiste esta disociación? Consiste esencialmente en un proceso de conflictividad con el cuerpo: el yo que se construye no va a asentarse sobre la base del cuerpo, no se logra la integración yo-cuerpo sino que se disocian. Esto es debido a que la no percepción y no satisfacción de las necesidades del verdadero yo, generan un proceso de consolidación de un yo patológico que va a estar en conflicto con los deseos del ello (cuerpo), resultando, pues, un yo disociado del cuerpo. Esta disociación debe ser entendida como una defensa: el falso self, que resulta o emerge en este proceso traumático de desarrollo del yo, defiende el verdadero self de un medio que no ha logrado reconocerlo. El resultado de este mecanismo de defensa es precisamente esa construcción del falso self, que crecerá alrededor del cuerpo (disociado de él), formando una cáscara que protege y aísla un núcleo vacío: el núcleo del verdadero self, cuya base es el cuerpo, pero que por su incomprensión por parte del medio no ha podido desarrollarse ni jugar su papel en la realidad. Ahora bien, esa protección y enterramiento del verdadero self no es consciente al falso self, que desconoce el proceso mismo de su constitución, convirtiéndose en un arma de doble filo: a la vez que el medio concede el privilegio de la individualidad (falso self), la individualidad que concede está escindida del verdadero self, que ineludiblemente está presente y amenaza a un falso self que no lo reconoce como suyo.

La disociación queda esclarecida en la escritura de Pizarnik a través de un proceso de replegamiento del ser y su correspondiente escisión, expresión poética de una experiencia vivida en sus propias carnes.

"Pero el silencio es cierto. Por eso escribo. Estoy sola y escribo. No, no estoy sola. Hay alguien aquíque tiembla." (Pizarnik, 2016).

Podemos intuir que Pizarnik habla de un yo escindido en dos: uno que escribe y otro que tiembla. De nuevo se expone el tema de la escisión a través de la temática de la fisura, la herida y la desgarradura del ser, como podemos observar en los dos siguientes pasajes.

"Cubres con un canto la hendidura

Creces en la oscuridad como una ahogada. 
Oh cubre con más cantos la fisura, la hendidura, la desgarradura."

(Pizarnik, 2016).

"Entre otras cosas, escribo para que no suceda lo que temo [...] Escribir un poema es reparar la herida fundamental, la desgarradura. Porque todos estamos heridos." (Pizarnik, 2013).

Este proceso de disociación lo encontramos descrito en los analistas de la obra pizarnikiana. Así nos dice Nuria Calafell: "El cuerpo, receptáculo y reflejo de esta invasión, experimentará una perturbación que obligará al sujeto a replantearse sus límites y a redefinir de nuevo su propia identidad: el yo (moi) que resultará de aquí será un yo escindido entre las fuerzas de atracción y repulsión que marcarán su relación con el no-yo, ese Otro anunciado por Julia Kristeva como "[n]o un otro con el que me identifico y al que incorporo, sino un Otro que precede y me posee, y que me hace ser en virtud de dicha posesión»" (Calafell, 2007). Esa invasión que menciona la autora en estas líneas, la describe Winnicott a través del concepto de imposición del gesto de la madre. Esta imposición actúa como un ambiente (no-yo) intrusivo, puesto que la madre coloca su propio gesto impidiendo que lo verdadero del cuerpo del bebé se realice (se haga real), quedando el gesto espontáneo del bebé mutilado, disociado. El falso self que resulta de este proceso de individuación traumático está ante una doble amenaza: por un lado, como hemos visto más arriba, esta disociado del cuerpo y amenazado ante su presencia, que le resulta extraña; por otra parte la identificación con el medio no es total, pues ese medio no ha sabido reconocerle sus verdaderas necesidades y el sujeto, aunque lo haya aceptado por medio del sometimiento, lo siente como invasión, pues no refleja su yo real. En este primer punto vamos a tratar la primera amenaza, aquella que se deriva de la conflictividad con el cuerpo, cuerpo que va a atraer al yo para reconstruirse sobre su base, al tiempo que, como venimos diciendo, va a amenazar al yo dada la escisión que hay entre ellos dos. Dejaremos para el segundo punto la segunda amenaza comentada proveniente del medio intrusivo.

En primer lugar, y ciñéndonos a esta relación conflictiva con el cuerpo, observamos que hay una búsqueda de identidad a través del cuerpo del que el yo ha quedado escindido. La desubjetivización vivida, la enajenación de sí, se traduce en Pizarnik en una vehemente búsqueda de una identidad a través del deseo de vuelta al cuerpo mediante la escritura.

"Deslumbramiento del día, pájaros amarillos en la mañana. Una mano desata tinieblas, una mano arrastra la cabellera de una ahogada que no cesa de pasar por el espejo. Volver a la memoria del cuerpo, he de volver a mis huesos, he de comprender lo que dice mi voz" (Pizarnik, 2016). 
"Todo mi ser aspira a una sola cosa: encontrar a quien yo sé, no en el sueño sino en el lugar de los cuerpos tangibles." (Pizarnik, 2013).

Entonces, cada vez que se acerca a la palabra se encuentra ante el abismo del vacío de sí misma y ante la (des)esperanza de, por fin, satisfacer lo que jamás fue satisfecho (aquel verdadero self que no fue reconocido por el medio). Al principio una esperanza pero, por repetidas desilusiones traumáticas (para aludir al lenguaje winnicottiano) a lo largo de su vida, acaba siendo una desesperanza.

Es además significativo que el lenguaje sea la vía de realización de aquellas necesidades más fundamentales del sostén, que la poesía materialice las necesidades fisiológicas con las que trata de reconciliarse el sujeto escindido. El siguiente fragmento lleva esa desesperanza que comentamos al terreno fisiológico del sostén: Pizarnik expresa la duda de si serán satisfechas esas necesidades fisiológicas, preguntando si con el lenguaje (instrumento que utiliza Pizarnik para materializar el cuerpo y satisfacer el deseo) podrá satisfacerlas.

"...no/ las palabras/ no hacen el amor/ hacen la ausencia/ si digo agua ¿beberé?/ si digo pan ¿comeré?/ en esta noche en este mundo/ extraordinario silencio el de esta noche/ lo que pasa con el alma es que no se ve/lo que pasa con la mente es que no se ve/lo que pasa con el espíritu es que no se ve/ ¿de dónde viene esta conspiración de invisibilidades?/ ninguna palabra es visible..." (Pizarnik, 2016).

Se trata, como nos muestra Calafell, de "lograr que el lenguaje y las palabras expresen lo inexpresable y hagan físico aquello que no lo es" (Calafell, 2007). Así pues nos encontramos ante múltiples referencias al sostén en las narrativas de Pizarnik a través de las constantes metáforas sobre el alimento y la comida, funciones básicas dentro del concepto del sostén en la teoría de Winnicott. Es interesante, por último, señalar que esta vuelta al cuerpo que observamos como temática recurrente en la poética pizarnikiana, adquiere en último término la forma de un necesario regreso al aislamiento.

"Como quien no quiere la cosa. Ninguna cosa. Boca cosida. Párpados cosidos. Me olvidé. Adentro el viento. Todo cerrado y el viento adentro." (Pizarnik, 2016).

Este regreso al aislamiento que tratamos de ejemplificar en el poema anterior es una forma de defender el verdadero self del medio que no lo comprendió y satisfizo: "Todo cerrado", "boca cosida". Nuria Calafell dice que estos órganos, como la boca, que tienen que ver con el alimento y bebida (sostén), se tiñen de un valor negativo puesto que se interpretan como lugares de pérdida de sí mismo de acuerdo con esa experiencia repetida de imposición del gesto de la madre, de avasallamiento del medio. El fin, el único modo de no desbordarse 
para Pizarnik, es, por lo tanto, cerrar los orificios para evitar esa pérdida del ser, para reconstruir el "soy" (Calafell, 2007). En palabras de Winnicott se entiende que este replegamiento mantiene el seguir siendo o la continuidad existencial a través del aislamiento.

Este aislamiento o replegamiento sobre sí marca las bases de un ensimismamiento (tendente al narcisismo) en la figura de Pizarnik, puesto que la mirada se posa recurrentemente sobre sí misma. Pero Pizarnik, en su núcleo interno, solo puede ver un cuerpo expropiado y enajenado, una muerte o ausencia de su ser. ¿Por qué? Como el sostén y la mirada son los posibilitantes de un existir real ("cuando veo que soy visto, existo" (Abello Blanco y Liberman, 2011)), cuando no hay sostén ni mirada, no hay un yo reconocido. Es por eso que mencionamos aquí ese replegamiento y esa mirada que se vuelve sobre sí misma a falta de una mirada del Otro (rostro de la madre), mirada que, o no estuvo, o estuvo pero no reflejó adecuadamente, pues puede que "el espejo [fuese] una cosa inanimada, algo que se mira, no algo dentro del cual se mira" (Bleichmar y Leiberman de Bleichmar, 2004). Es decir, la madre no cumple la función de espejo, de enseñar lo que el bebé crea o alucina. En el siguiente fragmento vemos cómo trata Pizarnik esa ausencia de la mirada así como su consecuencia: una pobre elaboración imaginativa (interpretación psicológica del cuerpo).

"Rumor de mis ojos mirándose mirar. Ello, para descubrir que la mano que oprime mi garganta es mía. ¿Quién me busca desde mi mirada?¿Quién me asfixia desde mis dos manos? ¿Quién se muere de sed porque no se le ocurrió nunca unir el acto de beber al de tener sed?" (Pizarnik, 2013).

Como hemos visto Pizarnik siente terribles deseos de escuchar su cuerpo con la posible finalidad de reconstruir la integridad de su ser escindido. Hemos mostrado a lo largo de este primer punto cómo su poética intenta hacer posible esa finalidad. Ahora bien, como hemos dejado entrever arriba, este movimiento que le conduce al centro de su ser, resulta contraproducente, pues le hace confrontarse con un cuerpo expropiado que ella no es capaz de reconocer como suyo. Es aquí donde podemos ver la ambigüedad del proceso: por un lado la atracción ineludible hacia el cuerpo como lugar de reconstrucción del ser, y por otro lado la repulsión ante un cuerpo que es vivido como presencia extraña y amenazante en cuanto realidad ajena al yo. Esta vivencia del cuerpo como algo extraño, algo que debe ignorarse, e incluso como algo muerto, lo vemos en las siguientes líneas, que muestran la otra cara del proceso que venimos analizando en este primer punto, proceso de atracción y repulsión hacia el cuerpo del que el yo se vio disociado. 
"el esfuerzo de ser es muy grande, el esfuerzo de vestirse de sí misma cada día y remontarse como a una ciénaga, arrastrarse como a un duro cadáver, bolsa compacta de chillidos y maldiciones y cosas muertas [...]" (Pizarnik, 2013)

\section{2. El espacio transicional en Winnicott: la imposibilidad de relación con el mundo externo en} Pizarnik.

En este punto vamos a describir la segunda de las consecuencias del sostén fallido. En el primer punto, al analizar la disociación, introdujimos el factor del medio para poder explicar por qué se producía esa escisión entre el yo y el cuerpo. El factor del medio es crucial, pues una mala lectura de la idiosincrasia del bebé por parte de la madre (medio), es la que provocaba una ruptura yo-cuerpo y la que provoca, como vamos a ver en este punto, una relación conflictiva con el medio. Por tanto, en este punto, desarrollaremos la relación yomedio.

La imposición del gesto de la madre funciona como una invasión que provoca una introyección desmedida del ambiente en el bebé. Esto significa que éste se somete a su medio, reprimiendo las verdaderas necesidades (escindiéndose de ellas) a costa de vivir en un mundo que opera con leyes totalmente fuera del alcance de su acción (someterse a las exigencias del medio). Para Winnicott el sometimiento encuentra su contrario en la creatividad. Creatividad se define como aquella capacidad para relacionarse con el mundo en la que el individuo se siente partícipe de los acontecimientos exteriores: hay una dialéctica interior-exterior. El desarrollo de la creatividad lo explica Winnicott a través del paradigma de la relación con el pecho de la madre: por un lado, presentando el pecho cuando el niño lo necesita, la madre favorece primeramente la ilusión de omnipotencia y seguidamente favorecerá una progresiva desilusión tolerable por esas repetidas experiencias favorables (el niño asimila medio como un no-yo favorable a sus necesidades); por otro lado, respondiendo de forma amorosa a los ataques instintivos agresivos del niño, la madre favorece la ilusión de transicionalidad (el niño confía en su capacidad para reparar). La contraparte de la creatividad es la complacencia o sometimiento. El sometimiento está marcado por la imposición del gesto de la madre, acontecimiento que provoca la negación de las propias necesidades para poder existir ante ella, que no acoge el gesto espontáneo del niño. Esto quiere decir que el niño introyecta el medio (un medio que le invade) y que no va a poder entender el medio como un espacio con el que poder hacer dialogar sus pulsiones más primarias. En definitiva no se genera un espacio transicional, y no se establece un vínculo con el mundo en que este se sienta como real y dotado de sentido para la vida de la persona adulta, que no será capaz de sentir esperanza 
en él (Abello Blanco y Liberman, 2011). En Pizarnik vemos que, al no experimentar ese vínculo como algo significativo, no desarrollará un ámbito de experiencia seguro y tranquilo. Pizarnik habla de un habitar que no tiene lugar "ni afuera ni adentro", haciendo ver que el espacio transicional, ese ámbito de experiencia del que hablamos, no cumple su función como espacio seguro, en el que habitar sea un hecho tranquilo:

"Dentro de poco me suicidaré. Siento claramente que estoy llegando al final. Veo cerrado. Ni afuera ni adentro. Simplemente no tengo fuerzas y la locura me domina (una histeria atroz: imposibilidad absoluta de quedarme tranquila)". (Pizarnik, 2013).

Además, la poética de Pizarnik está atravesada por el problema de la invasión o imposición. A continuación exponemos un poema donde parece estar describiendo una intrusión en su cuerpo, en su ser. La madre impone su gesto, ignorando los movimientos propios, su gesto espontáneo. Dice Pizarnik "me acometes", "me impides", como describiendo este proceso del que hablamos:

"velo, velo, velo tu cara, cara tu vela, carabela, obstetrica cara tétrica, me abres, me abres con tus ojos, goznes de mi cara, mis ojos, chirridos [...] me vela tu cara, me la velas, vé la la mía, véla amor mío, me abro, me abracadabro, me macabro, me recobro y me reabro, me repites, me impides, me acometes, me humedeces, me avientas, me [ilegible], me alucinas, me entreabres, me santificas, me bautiza." (Pizarnik, 2016).

Además, en muchos de los textos de Pizarnik se puede observar su percepción del mundo como algo inhabitable, así como su conciencia de gran imposibilidad y dificultad de relacionarse con el mundo y los objetos del exterior.

"Simplemente no soy de este mundo. Yo habito con frenesí la luna. No tengo miedo de morir; tengo miedo de esta tierra ajena, agresiva. No puedo pensar en cosas concretas; no me interesan. Yo no sé hablar como todos. (Pizarnik, 2013).

Por último, la poética pizarnikiana es un buen lugar para observar la percepción de persecución propia de una mala integración, y la percepción de ser odiada por todos como resultante de una organización del yo defensiva contra el ambiente hostil. "Nada me enlaza a la vida" dice Pizarnik en el pasaje que exponemos a continuación, en una muestra de esa ausencia de vínculos que le unan con el exterior: ausencia de vínculos con el mundo, pero también con los demás, como nos dice en el segundo de los fragmentos que recogemos, mostrando la ausencia de signos lingüísticos que no pueden comunicar la experiencia interna al exterior.

"Ayer y hoy, días suicidas. Estoy huyendo de algo. Nada me enlaza a la vida. Y ahora todo empeoró porque me siento perseguida y odiada por todos. No quiero vivir ni morir. Sólo tengo 
conciencia de una fuerte imposibilidad de todo. Además hay miedo de escribir. Yo no sé nada, no tengo nada que decir" (Pizarnik, 2013).

"Mis palabras son extrañas y vienen de lejos, de donde no es, de los encuentros con nadie..." (Pizarnik, 2013).

\section{3. El concepto de falso self de Winnicott: la futilidad de la existencia en Pizarnik.}

En los dos primeros puntos hemos abordado las dos relaciones conflictivas, con el cuerpo disociado y con el medio impositivo, que se producen a raíz de un fallo en el sostén; hemos tratado de alumbrar en Pizarnik la problemática de un doble vínculo conflictivo (consigo misma y con el mundo), a través del análisis de su poética. En este tercer punto queremos desarrollar la formación del falso self que no es sino la construcción artificial, a modo de prótesis del yo, necesaria para "existir" en el caso en que el verdadero self y el medio no pueden comunicarse.

Dentro de la teoría winnicottiana, el falso self posee muchas implicaciones en la vida psíquica de la persona. En La psicosis y el cuidado de los niños 1952 Winnicott describe el proceso de escisión que denominará escisión esquizoide de la personalidad (en verdadero y falso self), originado por el ataque del medio o fracaso de la adaptación activa del medio. Esta escisión es de la que venimos hablando anteriormente, que encuentra su origen en la falla de sostén desde etapas muy tempranas, y que es un intento de controlar el trauma vivido. Hablamos de un desarrollo patológico del yo donde la esquizofrenia está latente si la escisión es bastante pronunciada (Winnicott, 1999b). Nuria Calafell (2007) interpreta la esquizofrenia en los textos de Pizarnik en las variaciones de la persona verbal, a veces, sin transición alguna.

Habla de tu delirio. No sé si para liberarme, qué significa liberarse. Habla de tu delirio, de lo que deseas. Finalmente y como argumento para que te convenzas: los santos hablaron generosamente de sus deseos por quien no estaba junto a ellos. Pero yo no comprendo esta noche del alma. No sé con quién me deseo unir. (Pizarnik, 2013).

En caso de una escisión extrema entre la vida interior y el medio, ésta primera contiene muy poco de realidad, la vida interior es verdaderamente incomunicable (Winnicott, 1999c), salvo, como muestra Carlos Nemirovsky (2007), y como venimos comprobando en Pizarnik, gracias a la poesía.

Como hemos venido diciendo, el desarrollo patológico del falso self se edifica sobre la base del sometimiento. Contrariamente, un desarrollo saludable surge de la experiencia del núcleo del verdadero self, el cual nace de los tejidos del cuerpo. El gesto espontáneo sería 
la expresión de ese self verdadero, que en un desarrollo patológico no es acogido, sino que es reemplazado por el de la madre. El niño, si quiere existir para la madre, no le queda otra que aceptar el gesto de la madre bajo una actitud sumisa en detrimento de disociar su propio gesto espontáneo (Abello Blanco y Liberman, 2011). La vida real queda entonces disociada, y lo que es más importante para las experiencias vitales del falso self, se inhibe toda reacción que provenga de la vida instintiva.

"Alguien dejará de escribir pronto porque no habrá dolor para narrar. Te separaste y sonreías. [...] ¿Estás contenta? No es el contento a lo que aspiro sino a la carencia de deseos" (Pizarnik, 2013).

Aspirar a la carencia de deseos tiene sentido porque amenazan la continuidad del ser, pues en su momento no fueron acogidos y ahora se viven de forma intrusiva y aniquiladora. Vemos en las siguientes líneas que Pizarnik siente la enajenación de sí misma que ella expresa como carencia de libertad; esta enajenación es vivida como "represión", represión de los instintos que no es sino repetición por parte del falso self del gesto impositivo de la madre (medio).

"Mi carencia de libertad me aterroriza. Creo que no me atrevo ya ni a sentir frío si quiera. Mi silencio interno es motivado por una represión absoluta de todo pensamiento o idea. No me animo a juzgar o a meditar. Cada acto que realizo lo justifico en la medida en que se adapta a alguna imagen de mí que proyecté y que deseo realizar." (Pizarnik, 2013).

En último lugar, y como mencionábamos anteriormente, el falso self tiene como función proteger y esconder (silenciar) al verdadero self, impidiendo que este se vincule de forma creativa con el medio. Las interesantes consecuencias de la construcción de un falso self patológico, son sentimientos o experiencias de futilidad, irrealidad, vacío y sin sentido (Abello Blanco, A. y Liberman, A. 2011). Son estos sentimientos los que encontramos en la experiencia de Pizarnik.

"Creo que la melancolía es, en suma, un problema musical: una disonancia, un ritmo trastornado. Mientras afuera todo sucede con un ritmo vertiginoso de cascada, adentro hay una lentitud exhausta de gota de agua cayendo de tanto en tanto. De allí que ese afuera contemplado desde el adentro melancólico resulte absurdo e irreal y constituya "la farsa que todos tenemos que representar" (Pizarnik, 2013).

En este fragmento podemos observar dos cosas importantes: la primera, siguiendo la teoría winnicottiana, es la posible expresión de la melancolía como reacción ante el yo (el verdadero self) perdido; la segunda es la sensación de irrealidad y absurdo que caracteriza al falso self. 
II. 4. El miedo al derrumbe de Winnicott: la obsesión por la muerte en Pizarnik.

La angustia central de las problemáticas del falso self es el miedo al derrumbe (Abello Blanco y Liberman, 2011), último punto que queremos desarrollar a continuación. Winnicott distingue cinco angustias inconcebibles: fragmentación, caída interminable (miedo al derrumbe), separación psique-soma, pérdida del sentido de lo real y pérdida de la capacidad de relacionarse con objetos. Nos vamos a detener en esa angustia tan crucial que es el miedo al derrumbe, dado que es la más observable en la poética pizarnikiana.

El miedo al derrumbe es un tipo de angustia ya experimentada pero no recordada, es un derrumbe vivido en las etapas primitivas, experiencia que los mecanismos defensivos desplazaron al plano inconsciente, corporal, no quedando integrado en su organización yoica, por lo que la persona no lo recuerda. Por lo tanto, se trata de una angustia atemporal, no perteneciente al pasado, ya que la experiencia no fue recogida conscientemente pues no hubo nadie alli para recogerla, no había un yo (Winnicott, 1991). A continuación vamos a ver un fragmento de la poética de Pizarnik donde se pueden observar dos cosas relacionadas con este miedo al derrumbe: primero la experiencia del derrumbe como caída física, lo que se puede asociar con el caer interminablemente; y en segundo lugar, la ausencia de ese sostén de la madre que no estuvo allí para aliviar esa angustia.

"Mi caída sin fin a mi caída sin fin en donde nadie me aguardó pues al mirar quién me aguardaba no vi otra cosa que a mí misma." (Pizarnik, 2016).

En sus Diarios, la poeta también expresa una angustia difusa que es ilocalizable. Queremos reparar en ese carácter difuso tiene que ver con la atemporalidad de la angustia vivida, elemento que mencionábamos como esencial característica de la angustia inconcebible.

"Imposibilidad de describir concretamente lo que me atormenta. Siento que me acerco al final" (Pizarnik, 2013)

"Sé, de una manera visionaria que moriré de poesía. Esto no lo comprendo perfectamente, es vago, es lejano, pero lo sé y lo aseguro. Tal vez ya sienta los síntomas iniciales: dolor en donde se respira, sensación de estar perdiendo mucha sangre por alguna herida que no ubico..." (Pizarnik, 2013)

Además hay en Pizarnik un presentimiento de que se acerca el final. Esto lo interpretamos como un síntoma del cuerpo que está forzando por recordar esa muerte, que ya fue pero que no está integrada. El miedo al derrumbe se puede transferir a un miedo a la muerte. En ese caso, la persona busca la muerte compulsivamente, pero implícitamente está buscando esa muerte que ya sucedió, pero que no se experimentó. Esta lógica de Winnicott podría 
explicarnos el gran anhelo de muerte, convertido en una gran obsesión, en la obra de Pizarnik:

"Profunda, constante y obsesiva seguridad de que voy a morir dentro de unos pocos años" (Pizarnik, 2013).

"He abandonado todos los estudios. Trabajos. No me gusta trabajar. No quiero nada. Quiero morir" (Pizarnik, 2013).

Por lo tanto, y apoyándonos en las palabras de Nuria Calafell (2007), no podemos tomar el deseo de muerte como sinónimo de desaparición, sino como una reterritorialización corporal, es decir, una apropiación de su cuerpo.

Otro de los síntomas del miedo al derrumbe es la sensación de vacío. Winnicott en El miedo al derrumbe (1963), expone que, de la misma forma que sucede con la muerte, el vacío tampoco se recuerda; en esos pacientes sucedió un vacío cuando podría haber pasado algo (Winnicott, 1991). En el momento en que sucedió este vacío (etapas tempranas), la persona no sabía qué era lo que podría haber pasado, por lo que no pudo experimentarlo, sólo intuir que algo podría haber sido (ibíd.). Esta experiencia parece ilustrarse en los versos de Pizarnik:

Caer como un animal herido en el lugar que iba a ser de revelaciones. (Pizarnik, 2016).

Pizarnik parece intuir aquel "lugar que iba a ser de revelaciones", donde iba a suceder algo, pero en el que al final no sucedió nada. Ahora bien, Winnicott explica que el vacío es una condición previa del gran anhelo de recibir algo dentro de sí. El vacío está por un "antes de empezar a llenarse" (Winnicott, 1991). Las personas con este síntoma intentan experimentar ese estado de vacío organizando un vacío controlado: no comiendo o, todo lo contrario, comiendo de forma compulsiva (ibíd.)

"Tener el estómago lleno equivale, en mí, a la caída en una maldición eterna. Si me pudiera coser la boca, si me pudiera extirpar la necesidad de comer. Y nadie goza en esto tanto como yo. Siento un placer absoluto. Por eso tanta culpa, tanta miseria posterior". (Pizarnik, 2013).

El último rasgo que queremos destacar de este miedo al derrumbe es la angustia de la vuelta al momento traumático (diluidas las defensas): temor a la regresión y al no volver, reflejado en las siguientes líneas.

¿Qué haré cuando me sumerja en mis fantásticos sueños y no pueda ascender? Porque alguna vez va a tener que suceder. Me iré y no sabré volver. Es más, no sabré siquiera que hay un "saber volver". No lo querré acaso." (Pizarnik, 2013). 


\section{Conclusiones}

Con todas las ideas expuestas en este trabajo llegamos a la siguiente conclusión: se da en Pizarnik una pérdida de subjetividad como consecuencia de una falla, y una imposibilidad de su reconstrucción a través de los vínculos, utilizando la escritura para ese fin. Esta imposibilidad la hemos asociado, de acuerdo con la teoría de Winnicott, con esa falla ambiental en el vínculo madre-bebé (fallo en el sostén), que condujo inevitablemente a que se llevaran a cabo los mecanismos de defensa que, a su vez, generaron nuevas amenazas al núcleo del self. Las implicaciones manifiestas de esa pérdida de subjetividad en la poética de Pizarnik, provenientes de ese fallo en ese sostén, son fundamentalmente cuatro (siguiendo la teoría de Winnicott): la escisión del yo (disociación), la imposibilidad de relación con el medio, la futilidad de la existencia vivida desde el falso self y el miedo al derrumbe. El resultado es la expropiación del propio cuerpo que queda enajenado al no haber podido construir su verdadero yo sobre su propia base corporal, sobre sus sensaciones corporales, con las cuales, en cambio, se encuentra en conflicto. Se hace necesario la construcción de un falso self, como una cáscara alrededor del núcleo vacío, que es sentido y vivenciado como irreal, y al que acompaña una experiencia de futilidad y vacío.

Esta idea sobre la expropiación del cuerpo, sobre la ausencia de identidad y el sentimiento de no pertenencia al mundo, se relaciona y de alguna forma se complementa, con la hipótesis que Judith Vindel Sáez (2016) menciona en su trabajo acerca del desarraigo en la figura de Pizarnik como herencia de la naturaleza inmigrante de los padres. Un factor más que contribuye a esa ausencia de identidad y a esa condición de exiliada (Vindel Sáez, 2016). Por lo tanto pensaríamos en una doble condición de exilio; exilio del propio cuerpo, y exilio del lugar geográfico de origen, lo cual refuerza esa pérdida de identidad. Doble exilio del que Pizarnik intenta salir intentando reconstituir su identidad a través de la escritura, llegando a lo profundo de su ser; en palabras de Pizarnik: "No quiero ir/ nada más/ que hasta el fondo" (Pizarnik, 2016). Pero, aunque la poesía ejerciera de refugio o de instrumento para esa búsqueda de ese ser que nunca pudo ser, finalmente pareció no servir de alivio a su profundo sufrimiento, y el abismo fue el que imperó en esa lucha: Pizarnik acabó suicidándose en 1972, a los 36 años.

Con este trabajo se han establecido diversas relaciones entre la teoría de Winnicott y la poeta argentina, y también se ha conseguido comprender ciertos aspectos de la obra y figura de Pizarnik con ello. Pero esto solo es una pequeña mirada hacia la poeta, pues en ella se encierra una complejidad inabarcable. Esperamos que tras la reflexión de este trabajo y tras las conclusiones que se han sacado, se puedan abrir interrogantes que puedan dar a luz trabajos futuros. Me gustaría apuntar tres de esos posibles interrogantes futuros. En primer lugar, la posibilidad de analizar el patrón central de relación de Pizarnik a través 
de sus narrativas, tarea que nos daría información relevante acerca de su vínculo primario. En segundo lugar, poder dar pie a reflexionar en un futuro la función poética como apaciguadora del sufrimiento (¿por qué la escritura no salvó a Pizarnik?). En tercer y último lugar, estudiar la relación que hubo entre Pizarnik y el psicoanálisis. Esta última tarea es interesante no solo porque Pizarnik, como intelectual, se vio interesada por la corriente psicoanalítica, sino también porque se psicoanalizó con Leon Ostrov durante unos años; además, sus dos lugares de residencia, París y Argentina, fueron países donde el psicoanálisis estuvo en alza en esa época.

\section{REFERENCIAS}

Abello Blanco, A. y Liberman, A. (2011). Una introducción a la obra de D. W. Winnicott: Contribuciones al pensamiento relacional. Madrid, España. Ágora relacional.

Barthes, R. (2004). Citado por Calafell, N. (2007). Sujeto, cuerpo y lenguaje: los diarios de Alejandra Pizarnik. (Tesis doctoral, Universidad Autónoma de Barcelona). Recuperado de: https://ddd.vab.cat/pub/trerecpro/2007/hdl_2072_4349/Treball_de_recerca.pdf

Bleichmar, N. y Leiberman de Bleichmar, C. (2004). El psicoanálisis después de Freud: Teoría y clínica. Barcelona. Paidós.

Calafell, N. (2007). Sujeto, cuerpo y lenguaje: los diarios de Alejandra Pizarnik. (Tesis doctoral, Universidad Autónoma de Barcelona). Recuperado de: https://ddd.uab.cat/pub/trerecpro/2007/hdl_2072_4349/Treball_de_recerca.pdf

Magliano, C. (2005). Alejandra Pizarnik: una poética del yo al yo. Revista Uruguaya de Psicoanálisis.

Nemirovsky, C. (2007). Winnicott y Kohut: nuevas perspectivas en psicoanálisis, psicoterapia y psiquiatría: la intersubjetividad y los trastornos complejos. Buenos Aires. Grama Ediciones.

Vindel Sáez, J. (2016). Tristeza y dolor en la poesía de Alejandra Pizarnik. (Ensayo para BA, Universidad de Islandia). Recuperado de: https://skemman.is/bitstream/1946/26096/1/TESIS.pdf

Winnicott, D. (1991). El miedo al derrumbe. En Exploraciones psicoanalíticas I. Buenos Aires. Paidós. (Versión original 1963)

Winnicott, D. (1999a). Objetos y fenómenos transicionales. En Escritos de pediatría y psicoanálisis. Barcelona: Paidós Ibérica. (Versión original 1951)

Winnicott, D. (1999b). La psicosis y el cuidado de los niños. En Escritos de pediatría y psicoanálisis. Barcelona: Paidós Ibérica. (Versión original 1952)

Winnicott, D. (2006a). La integración del yo en el desarrollo del niño. En Obras escogidas I. Barcelona: RBA Coleccionables. (Versión original 1962).

Original recibido con fecha: 10/9/2018 Revisado: 22/10/2018 Aceptado: 30/10/2018 